\title{
A Designer on Designing: A Conversation with Johannes Torpe
}

\author{
Marc Stierand' (D), Jérôme Heelein', \\ and Charalampos Mainemelis ${ }^{2}$
}

\begin{abstract}
Organizational research has explored how design thinking can fulfill the human needs of customers or users, but it has largely overlooked how it is shaped by the designer's subjective experiences. In an attempt to stimulate greater scholarly interest in exploring the designer behind the process of design thinking, we integrate materials from three interviews conducted with the renowned designer Johannes Torpe. Throughout the interviews, Johannes stresses the interpersonal aspects of his work, especially how he interacts with customers and how he fosters (and also controls) the creativity of the other designers that he employs in his studio. As our conversation unfolds, Johannes responds to our questions as an evolving creative person, a celebrated designer, a manager of a creative collective of designers, a top designer employed by a large corporation, and a business owner of a celebrated Danish design studio.
\end{abstract}

\section{Keywords}

creativity, interviews, qualitative research

\section{Introduction}

Just shy of a decade ago, the CEO and President of IDEO, Tim Brown, announced in his Harvard Business Review article that " $\mathrm{t}$ ] hinking like a designer can transform the way you develop products, services, processes - and even strategy" (Brown, 2008, p. 1). This way of thinking like a designer became generally known as design thinking and while the concept itself is not new, its application in management and management education is rather recent. Design thinking is distinct from design for it is the mental processing in design work that ultimately leads to design (Dunne \& Martin, 2006), meaning the "products, services, buildings, organizations and environments which meet people's needs" (Chiva \& Alegre, 2009, p. 424).

Design thinking, "the application of human creativity to a purpose" (Chiva \& Alegre, 2009, p. 424), has been conceptualized as a process consisting of a few recursive stages, such as inspiration, ideation, and implementation (Brown, 2008), or discovery, definition, ideation, and delivery (Gruber, de Leon, George, \& Thompson, 2015). In essence, it is:

[A] human-centered approach to innovation that puts the observation and discovery of often highly nuanced, even tacit, human needs right at the forefront of the innovation process . . .. At the heart of design thinking is the primacy of the customer or user experience, and that the products, services, processes, organizational design, and business model should be designed to enable that compelling experience, rather than the other way around. (Gruber et al., 2015, pp. 1-2)

To date, organizational research has explored how design thinking can fulfill the human needs of customers or users, but it has largely overlooked how it is shaped by the designer's subjective experiences. The lack of attention on designers as sources of variability and creativity is peculiar, considering that the design thinking literature posits that a designer's sensibility plays a key role in matching people's needs with what is technologically feasible and strategically acceptable (e.g., Brown, 2008; Stephens \& Boland, 2015). There are even cases where it is virtually impossible to dissociate the identity of a creative work from the creative identity of its designer. For example, Cameron (2003) described the creation of a controversial building for the Weatherhead School of Management as "a one-of-a kind creation of an architectural and artistic genius," namely Frank Gehry. Further unpacking the complexity involved in designing in order to fulfill the human needs of customers or

'Ecole hôtelière de Lausanne, HES-SO University of Applied Sciences and Arts Western Switzerland

${ }^{2}$ ALBA Graduate Business School, Athens, Greece

\section{Corresponding Author:}

Marc Stierand, Ecole hôtelière de Lausanne, HES-SO University of Applied Sciences and Arts Western Switzerland, Route de Cojonnex 18, Lausanne 25, $\mathrm{CH} 1000$, Switzerland.

Email: marc.stierand@ehl.ch 
users, Weick (2003) observed that Gehry's customers often do not know what they want, or what they say they want is what they already have. Customers, writes Weick (2003), are often bewildered and scared by Gehry's models, and even Gehry himself often doesn't know what he wants (see also Bennis, 2003).

By focusing on the work of just one idiosyncratic architect and his team, Weick (2003) managed in effect to persuasively show that the design process is more messy and fluid, and less orderly and planned. This has been further confirmed by several professional designers who have suggested that design thinking, in particular, is too outward (Simpson-Little, 2016), confusing (Lahey, 2017), not really new (Vinsel, 2018), obsessed with prescription (Jen, 2018), and fundamentally conservative (Iskander, 2018). Within the professional designers community, design thinking is often believed to preserve the status quo (Iskander, 2018) and promote only incremental innovation (Nussbaum, 2011) that often results in copycat products that lack uniqueness and differentiation (Ersoy, 2018). Within the organizational scholarly literature, Stephens and Boland (2015, p. 224) observed that "in sum, these criticisms point out that it is overly simplistic to import a set of designthinking practices (e.g., sketching, role-playing, prototyping) and expect their use to automatically resolve 'wicked' problems in an organization."

We stress that what these critiques question is not necessarily the value of design thinking as manifested in the sensibility of designers, but the extent to which the process of design can be reduced to a set of prescribed steps that can be executed consistently and reliably regardless of the sensibility of the designer. It appears that professional designers (as well as academics, e.g., Stephens \& Boland, 2015) are asking us to consider that design thinking is an act of human creativity that cannot be properly grasped without elucidating the subjective experiences of designers themselves. In this regard, Dunne and Martin (2006) explicitly mention three aspects that seem to be essential when framing design thinking: cognitive aspects (i.e., how the generation of ideas, their analysis and evaluation are combined through the designer's reasoning), attitudinal aspects (i.e., how the designer's attitude toward constraints differs in comparison to standard management thinking), and interpersonal aspects (i.e., how the designer empathizes with the users' and peers' needs and perspectives). In addition, Stephens and Boland (2015) discussed the role of aesthetic knowing, especially how designers use their emotions and bodily senses to experience, define, and resolve design-related problems in a holistic way.

In an attempt to stimulate greater scholarly interest in exploring the designer behind the process of design thinking, in this article, we integrate materials from three interviews conducted with the renowned designer Johannes Torpe, owner and creative mastermind of Johannes Torpe Studios in
Copenhagen (www.johannestorpestudios.com). The interviews were conducted on March 21, 2015; December 7, 2015; and December 17, 2018, and in these interviews, we asked Johannes to talk about the life path that led him to design; the design process that he and his team use at Johannes Torpe Studios; and the role his personal creative identity plays in the products that he and his team design. Throughout the interviews - and we realized this only with hindsight - Johannes stresses the interpersonal aspects of his work, especially how he interacts with customers and how he fosters (and also controls) the creativity of the other designers that he employs in his studio. As our conversation unfolds, Johannes responds to our questions as an evolving creative person, a celebrated designer, a manager of a creative collective of designers, a top designer employed by a large corporation, and a business owner of a celebrated Danish design studio.

\section{The Interview}

As previous research on creative individuals has indicated, it is important to consider a creative individual's socio-cultural context when interpreting their work philosophy (e.g. Mainemelis, 2010; Mainemelis, Kark, \& Epitropaki, 2015; Stierand, 2015; Stierand, Dörfler, \& MacBryde, 2014). Torpe was born and raised by bohemian parents in a hippie commune in Denmark. Without much formal schooling, he left home at the age of 12 years to play the drums. A self-taught designer, he created his first and successful lighting design business in Denmark at the age of 17 years. In 2000, Torpe and his brother formed the music duo Artificial Funk that in 2007 produced the number one hit "Calabria", which sold over 10 million copies (Ben-Yehuda, 2008). In 1997, Torpe set up his design studio in Copenhagen and for a while also ran an office in Beijing. Having won many accolades and international fame for his studio's creative designs for various clients (some examples are shown in Figures 1-6), Torpe was also the Group Creative Director of the iconic Danish firm Bang \& Olufsen from 2011 to 2015.

\section{Attitude toward Constraints}

We note earlier that past research has stressed the role of attitudinal aspects in design thinking, especially how the designer's attitude toward constraints differs in comparison to standard management thinking (e.g., Dunne \& Martin, 2006). Reflecting on his upbringing, Torpe told us that his attitude towards constraints in life underlies his attitude towards constraints in the design process. He further stressed that his attitude towards constraints has not been static over time, but rather, it has evolved as a result of growing older and more experienced. Torpe also emphasized the role of emotions and holistic experience in the design process (cf. Stephens \& Boland, 2015). 


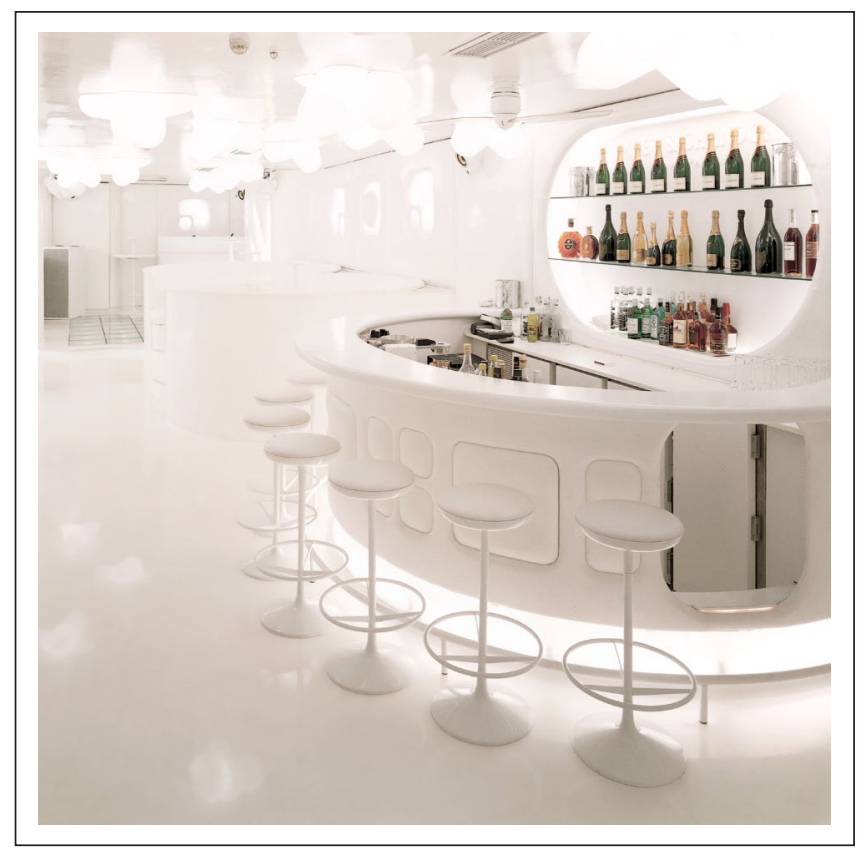

Figure I. Interior design, NASA nightclub, Copenhagen, Denmark, 1997.

"The private members club NASA was designed as a futuristic ode to Stanley Kubrick's '200I: A Space Odyssey'. It is kept in a strictly white colour scheme, with consistently soft, organic shapes. Every detail was designed especially for this club, from the ashtrays to the doors." Excerpt and photograph from www.johannestorpe.com.

What makes design different from music?. When I was a kid I had two choices. One was to accept the conditions I was born into. I was raised in a hippy camp where people were smoking cannabis and not really doing anything with their life. The second choice was to let the passions that I had rule me. The passions I had were music, because of my father who was a musician, and design, because of my mother who is an artist. Being an artist didn't really give me goose pumps, whereas something where you can actually put the dots together and actually make something that is more commercial excited me. Design is exactly this. You grow with design, you age with design. Sometimes with music you don't mature, because if you have to succeed in the world of music, youth is a very important thing. Seeing myself standing in front of 20,000 people, playing electronic music at the age of 50 would be somewhat embarrassing to me.

I am good at three things in my life: I am really good at communicating, I am really good with design, and I am really good with music. I think I reached my peak with my music. It has been a fantastic journey, and it is still going on, but it is going on at a different level. A level where in the past it was very much to pursue making something that would be recognized in the world, something which is a powerful thing. And music is! And now it is more about making beautiful music that can enlighten your world, enjoying the journey, not the destination.
When you are younger, the destination is more your focus. When you become older, you are more like, "ok, the destination has been interesting and now it is the journey." Because the rest of the life is the journey. I started to focus on what is my true interest. It is for sure design. Music is a natural part of my life, and it is a humongous part of my story as well. It has been very beneficial, it has been great, but where my heart lies and my focus goes is to create something where the design is the sum of its parts. I think this is really my ultimate goal as a designer.

So, it is a matter of emotion in fact?. Oh yeah it is. I think that everything is very emotional and very connected to being true to what you feel, and what I feel is to take my design and make it shine and grow with it. I believe very much in organic growth. If you do it organically, people will recognize you because you become damn good. In the music business, you often find what I call "gold diggers": I am not talking about girls with plastic boobs and silicon lips, I am talking about people who are always searching for the next hit, and the same goes on in design as well. Following trends does not really interest me. What interests me is to do something that will, over time, enhance people's experience through design. This is something that is quite easy to pursue if you focus on the experience and not on becoming famous.

I think that many people are goal oriented: "you have to reach this by this time". The older you get, the more you realize that if you don't reach your goals it is ok. Goals are something you set for yourself to know if you are on the right track. If you work for the goal to become a CEO or a vice president, you will retire in boredom. If you have your own business, your ultimate goal is to live a happy life and do something that is meaningful for you and for the people around you. That's really it.

I enjoy the journey and the journey is not the deliverable. The deliverable is the result of the compromises in the journey. So, designing, as well, is about compromises. Compromises about extracting your idea to a higher goal. And when you deliver something, you deliver it on the basis of the clients. It is a very important lesson as a designer.

If you already know from the brief all the boundaries that are technologically possible, you do not feel that this diminishes your creativity? Well, creativity is also about compromise. If you want complete freedom, you limit your ability to ever get anything done in this world. You will find engineers constantly challenging your ideas and actually allowing you to get to where you want to go. When you are young, you think that you know what is right and they just have to shut up. It is similar to the starving artist's way of looking at things. Never compromise, just do it the way you want to do. Once you get more mature, you learn that it is impossible to do what you want to do and to get a product out there through an industrialization process. The compromise feels even greater 

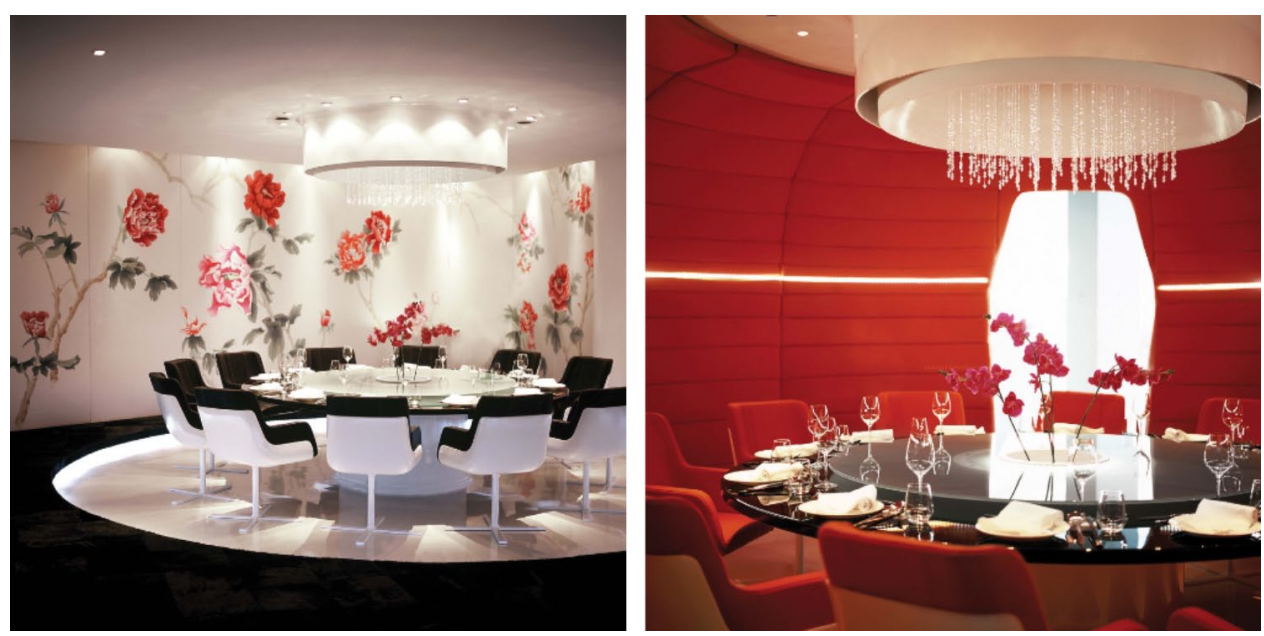

Figure 2. Interior design, Subu restaurant, Beijing, China, 2008.

"Traditional components of Chinese design sparked the inspiration for the design of the fine-dining restaurant Subu. Fused together with the Scandinavian design style we created a universal aesthetic with strong references to Chinese culture and traditions like the concept of 'private dining rooms'." Excerpt and photograph from www.johannestorpe.com.

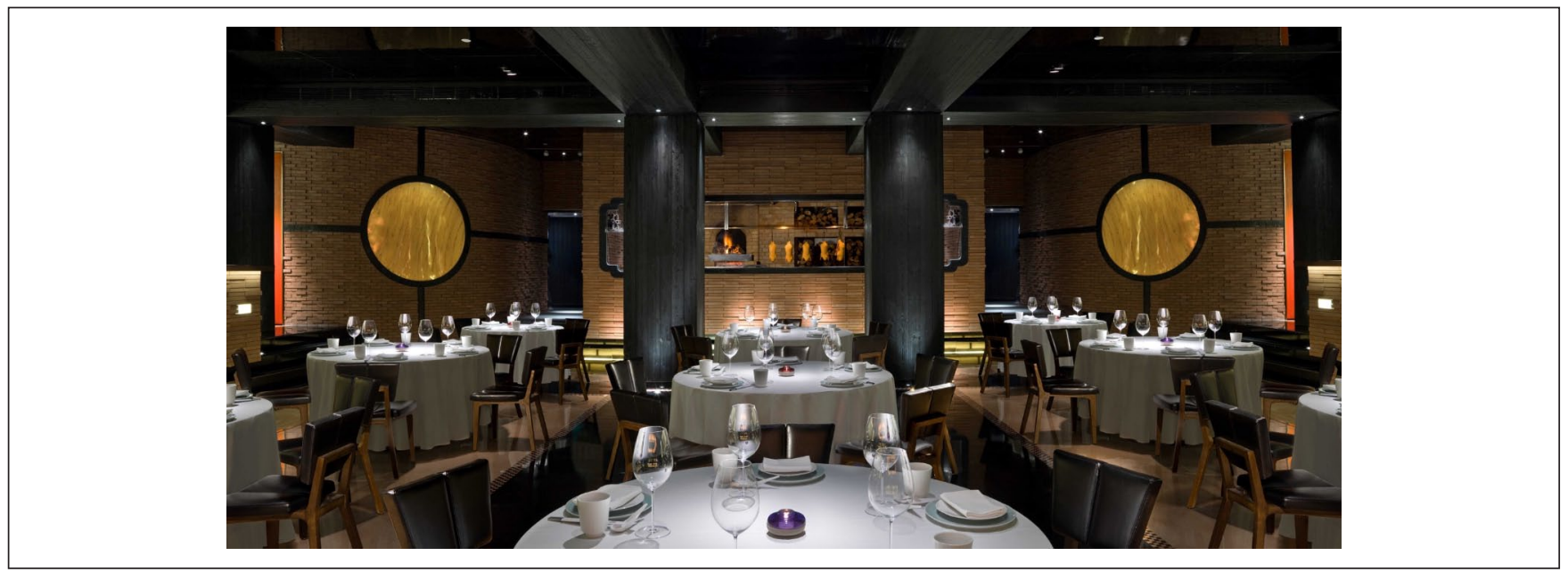

Figure 3. Interior design, Jing Yaa Tang restaurant, Beijing, China, 2013.

"In collaboration with infamous London-based restaurateur Alan Yau, for his first ever restaurant in China, we created a restaurant that brings a contemporary, theatrical design to the dining experience of traditional Chinese peking duck." Excerpt and photograph from www.johannestorpe.com.

if you know from the beginning what you want to do and how to get it to where it has to go.

I guess it is also exciting to be creative within constraints?. Exactly. It is understanding who you are being creative for. Is that for yourself or is it for a customer? And who is the customer? How can you offer that customer your creativity so that he or she can absorb it? If it is unlimited creativity, nobody understands it. As a chef, if you just get complete freedom, you might be able to please the other chefs who think you are fantastic. But to be able to take that creativity and transform it into something that everybody would like, that takes also the skill of the marketer and the skill of making the impossible possible. But one thing is a meal that is an experience, you come in and you have it once. Another thing is if you create a product - it could be a smartphone or a laptop - then the functionality has to be understood completely before you can do design innovations, because it has to be something that is actually relevant to the people that want to buy it.

\section{Empathizing with the users' and peers' needs and perspectives}

Torpe's comment about the importance of "understanding who you are being creative for" reflects the importance of interpersonal aspects in the design process, especially how the designer empathizes with the users' and peers' needs and perspectives (Dunne \& Martin, 2006). Torpe expressed the 


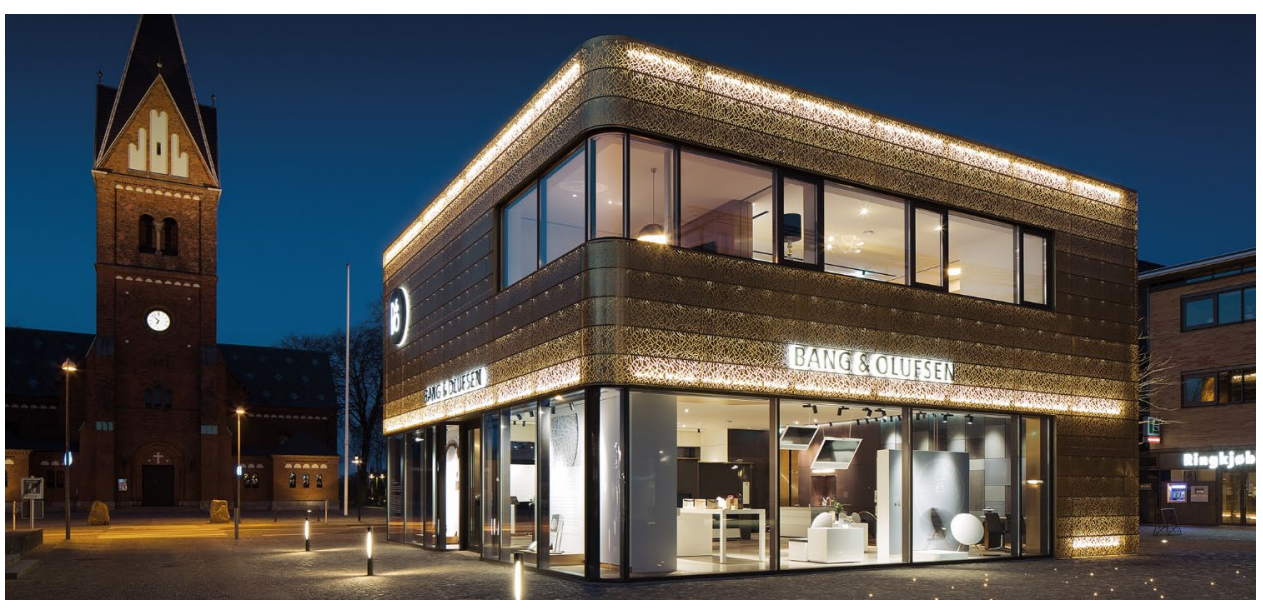

Figure 4. Retail design, Bang \& Olufsen Nexus Flagship Store, Herding, Denmark, 2014.

"A building uniquely created around the new Bang \& Olufsen store design, Nexus was named after the Latin word for 'unity'. It is the first Bang \& Olufsen store to utilise the holistic nature of the company's new retail concept; integrating architectural design, store design and products under one roof." Excerpt and photograph from www.johannestorpe.com.
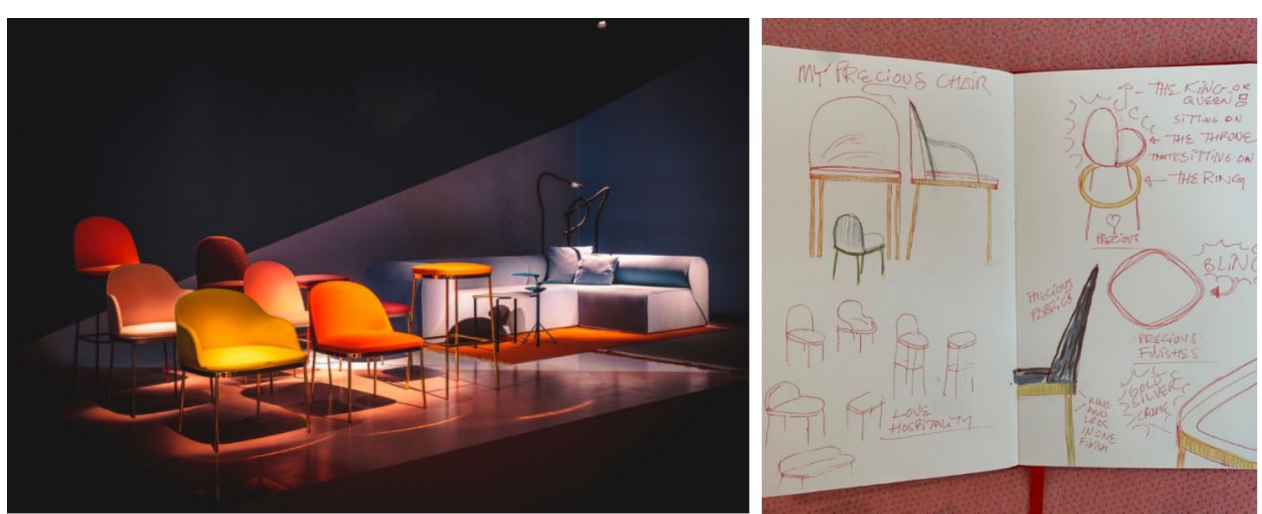

Figure 5. Product design, Moroso Precious Chair and Heartbreaker Sofa, Italy, 2019.

"Designer Johannes Torpe has created a series of whimsical furniture for Italian furniture brand Moroso, inspired by a relationship and its breakup. Torpe references a past relationship in both the Heartbreaker sofa and the Precious chairs and stools. The Precious seats were designed while Torpe was 'in a moment of love and happiness' and planning to propose marriage. Both chairs and stools are wrapped by a thick metal band, like a wedding ring, that runs around the base of the seat cushion. The Heartbreaker sofa was designed after the relationship fell apart, leaving Torpe heartbroken. Half-heart shapes form the end of each of the armrests on the modular sofa, making it appear broken until two ends are pushed together to form a whole . ... 'If you know the story and you look at the sofa, it gives you an emotional connection to the product', Torpe explained. 'I think the world really does need authenticity, and storytelling that actually is true," he added. "It's not about marketing. . ..' 'If a songwriter can put his or her heart on a silver plate and serve it to people, why shouldn't a designer be able to do the same?' he asked." Excerpt from Dezeen (2019). Photographs from www.johannestorpe.com.

view that, because success in design emerges from the quality of the relationship between the designers and the customers, he is very careful when it comes to choosing projects and customers, as well as design collaborators in his studio.

What do corporations do wrong when it comes to creativity? They tend to get rid of all the people who have the authenticity of the company. They get rid of their quirkiness and their emotions. Then you also kill the brand, and the only thing you have left is a brand name and people's interpretation of what they get from acquiring something from that name. Then corporations bring in consultants. The employees call it the "Tuesday-Quarter-Past-Nine Sound." It's like highheeled shoes walking towards you can hear the consultants walking in.

Where does your passion for design come from? I have a passion for life and I have a passion for people. I think people are interesting. What is the interesting thing about it? It is that the energy that I get from other people is generating my 

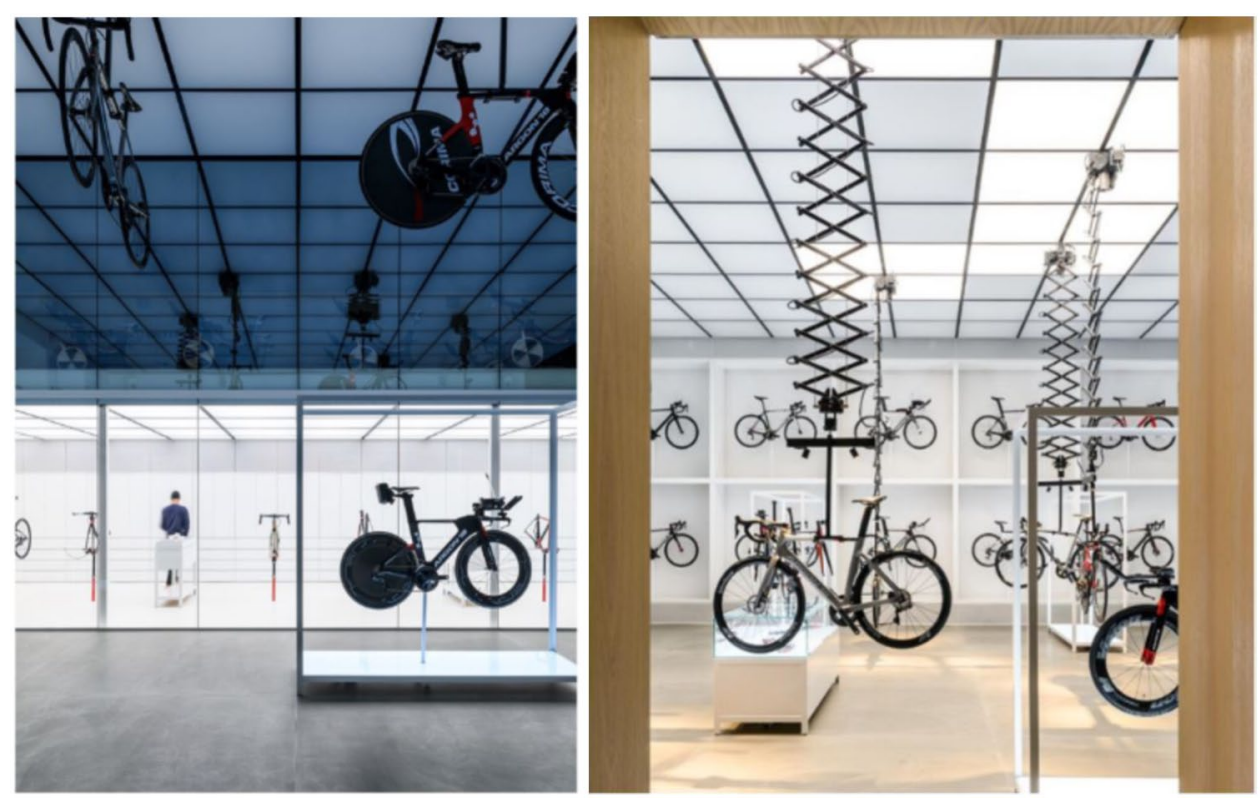

Figure 6. Interior design, United Cycling Lab \& Store, Lynge, Denmark, 2018.

"Johannes Torpe Studio aimed to create the aesthetic of a 'futuristic lab' with this bike store near Copenhagen, which features illuminated white walls and mechanical hoists attached to the ceiling.

The store is located in the small town of Lynge, in Denmark, in a building that since the 1990s has been exclusively used as a storage facility by United Cycling, a distributor of high-performance bicycles to advanced cyclists and athletes. Keen to expand the business, United Cycling approached Copenhagen-based Johannes Torpe Studio to turn the I,650 square-metre building into a retail space and headquarters for the brand.

The interiors now play host to a product showroom, workshop, and a bike-fitting area for customers, as well as a number of meeting rooms and a canteen for staff.

When it came to designing the main showroom, the studio wanted to encourage customers to 'inspect, touch and admire the bicycles for their technical superiority'.

It was decided to divide one of the six-metre-high walls into eight large display boxes, which have then been back-lit to draw further attention to the products. . .

'The result is a clinical and futuristic lab - a toy store for the passionate and serious rider. We call it a modern monastery for the science of cycling', explained Johannes Torpe Studio.

Several other bikes are shown at floor level inside white square frames, while five models are suspended from the ceiling on mechanical hoists that can be lowered at the press of a button should customers want to take a closer look. .

'The design concept circles around the contrasts between nature and science and the meeting between man and machine,' the studio added." (https:// www.dezeen.com/2018/I I/06/johannes-torpe-studio-united-cycling-shop-lynge-denmark-interiors/)

Photographs from www.johannestorpe.com.

ideas and fueling my creativity. My ideas have been $100 \%$ influenced by other people around me. You don't simply wake up and have a great idea. If you really think back, you realize that a person said something that made you think.

That's why I've never understood those people who say "ok, I'm going to go back for a few months and isolate myself and clear my mind." I clear my mind by listening to other people and not talking about myself. In that way it makes me relax and inspires me a lot if the person is inspiring. I can determine that within 30 seconds. It is very easy. It is a feeling.

How do you include your passion for people in the design process? If you work for someone who trusts your opinion, then you have to deliver what is best for them, not what is best for yourself. So for instance, if I do a three-star hotel for someone, I should not let my ego outshine the concept. If I follow this rule, I will do a hotel where I myself would like to stay. I have to consider what is good for them, and if what is good for them is less eclectic, less designed, more practical, because it is an operational question, this is my highest priority to do; to really give them the value they deserve. If I am a good consultant, I give them what they need and what they are capable of doing. So, if you place your vision over the head of people who are not able to carry it out, then you will not be successful. It is bad business. You have not analyzed your client well enough to give them what they actually need. I think this is a very pragmatic way to do ethics. You can also just not care, but I do care about it. And I think empathy in business is a very important thing. If you don't approach people with empathy then you end up misusing their trust. Design is always a compromise. If you don't put your soul into it, it is just a job. 
How do you decide whether to take on a project or not? I like to meet with people and understand where they come from, understand with a good heart. That is why it is difficult to work with a corporation, because you do not deal with people but you deal with brand guidelines. You deal with something that is a set of rules, which someone in a corporate office set for you and you have to fill in the space in-between. Mostly. That is why I think it all depends on the people around. So that is why I really enjoy a family-oriented background with people behind. They choose you not because you are a designer or an architect; they choose you because you are you! Whereas in the corporate world you do not choose like that. You choose by procurement, by price, by timelines, by all the things that in the end do not make a difference!

You can get a mediocre piece of work by a company that can deliver on a timeline, but then the validation of the creativity is completely wrong. That is why I think it is really, really, really important to choose the people you work with very carefully.

So, when you are a creative like me, it is very easy to say: "This is the way it is!" Wherever you put your boundaries is up to you, but to follow the rules just because they are rules is not interesting. I think rules exist because you can break them. Otherwise, your goal should be to reach mediocrity and to make something that is good for everyone.

How do you foster creativity in your team? In my team it is very much about freedom. If our people do not have freedom to create, and if I dictate what I want, then my ideas do not get challenged. I like things to be challenged, because I know that my ideas can be strong, but you have to validate your ideas. I think that this is a very important thing to realize. This way it is very clear for me to see and to pick and say: "for this to work, you have to do this or this." So, I become more like a curator. I think the curating role is what you want to achieve if you want to work for a lot of different companies and services. You need to be able to curate. For me it is very important to give freedom as much as responsibility. If I give you freedom, you are responsible for your work, but if you do not perform, then you have to face the consequences. I call it freedom over responsibility and I think this is a good way because I think it allows people to grow and it allows people to be very present, and I can feel very easily when I meet a person that has the ability to grow: they shine.

It is all based on trust. $100 \%$. So, trust is really an important thing and I trust people until they prove that I cannot trust them. If I have to micromanage so many people, then I cannot work properly. It is a very tiring thing. But when I see people love performing I will guide them in a very nice way . . . If it is about design, I like to be challenged from here to the moon. But I also know when I need to say: "thank you for the challenge, but this is the way it should be done!" Because,
I know this is the way it will work for a company or a person. I have to find a way to make it fly. That is pragmatic.

And what happens if one of the members of your team transgresses your instructions because he or she wants to go in another creative direction? This happens all the time and it is a really good thing. Sometimes, something fantastic comes out of it. But what people have to understand is that it does not matter if it is my idea or it is their idea. It is always a contribution to a bigger vision. They have to respect where I come from. They know I have like, of my 42 years, I've been having businesses for 27 years, which is extraordinary. Normally I would be 65 to have that, but I am not and that is also something that in the beginning, new people come in, they are like: "I am an architect!" They think they don't have to prove themselves and that I am the one who has to prove himself, because they come and they are like: "You have no education, but I do, so I know." So, I am like: "Hah, here we go again" and we have to go through the same process again of them understanding what we have done hereI actually did it!

So, you can have all your education, you may have been an $\mathrm{A}+$ student but it does not mean you are ever going to build anything. We have many times here, where people come in and tell me: "I am an architect and this is not good architecture!" Then, I would have to stand up and say: "Ok, I understand we have problems in our team. The orchestra is not playing well and that means I have not been conducting it well and somebody has been taking charge of the direction. So, if you come in here and you make the orchestra play badly, you are not a part of the team." So, I can be a great conductor but if I do not conduct hard enough, if I do not tell some of those people I want you to play that, then I have to let them go.

\section{Reasoning about Generating, Analyzing and Evaluating Ideas}

Research on the cognitive aspects of design thinking focuses on how the generation of ideas, and their analysis and evaluation are combined through the designer's reasoning (Dunne \& Martin, 2006). It appears, however, that designers have to also reason about the internal challenges that they face in their own organizations. In the industrial and product design business, and in the creative industries more generally, a distinctive creative identity is often the most important source of competitive advantage of a product, service, and/or organization (Bennis, 2003; Cameron, 2003; Jones, Anand, \& Alvarez, 2005; Lampel, Lant, \& Shamsie, 2000). We asked Torpe how he balances the tension between serving the needs of his customers while also preserving his own creative identity as designer, as well as the tension between preserving his own creative identity while also fostering the personal creativity of the individual designers that he employs in his studio. 
Would you do any project without having your creative identity in it? Yes. We do many projects that do not have my personal creative identity in it. But, I think it is also important to understand what the customer or the client needs. What is actually their problem? How can we solve their problem, but solve it in a creative way, not in an $\mathrm{A}+\mathrm{B}+\mathrm{C}+\mathrm{D}=\mathrm{Z}$ way. It has to be done in a way where the main function of what we do is that we do the right thing for the client in a creative way that kind of brings the creativity up in the business as well. If the client comes and says "I want this", and after we do our analysis we say, "well, actually you might need something different" and they respond "no, you're actually wrong, we want this so make this for us," then we might have to say "no, thank you," because if they have already identified what they need and how it should be done, then they could just well do it themselves. Whereas if we can help them identify what they really need and do it much better and rejuvenate their business through design, then we have done something really good. So, I would say that we focus more on their needs and how we can help them change creatively.

Can you see in the things themselves the creative identity of the person who has designed them? How do you build your own creative identity as designer into a more standardized, common design process? An old employee of mine told me recently that in the beginning, when he came to work in my studio, he had to get used to work for me and to draw the acts. He said, well you have a very, very specific way of doing things that is very much you and you actually reject everyone else's style until people recognize what they have to do to draw what you do. I was actually a bit surprised, but I think he is right. It took him three months to understand what I want. He stopped working in my studio years ago, he has worked in three other places ever since, and he said that in each of these studios it took him an equal or even a longer amount of time to learn how not to draw what he had been taught before. When you come into one place where you have to work for someone else, like if you work as a chef but you work for a famous chef, you have to make his food, not your food. You have to make his food first and then you can improve and put your input into it. I guess that is how it is with all creative processes, you have to find out what is your creative DNA. To have that creative identity is something that you grow over time.

What do you think about large industrial design companies like IDEO, who have basically standardized their whole creative thinking process? They started as small creative companies, but now they are big consulting firms that help big companies solve problems. A company comes in with a problem and they are like the McKinsey \& Co. of design. It does not matter if the customer comes and says design us a laptop or design us a boat. They can do all of it because they treat the project in the same way. McKinsey treats the process of helping a big company that needs to do a turnaround. I believe what IDEO does is very skillful and good, but I don't see them challenging anything creatively.

How important are your subjective experiences and your emotions, all these very personal things that you talked to us about earlier, when you have to make compromises for business reasons? If there is an inner desire to do something creatively that carries your personal signature, how do you bring that in? There must be an inner struggle. Yes and no. Not really. There are different approaches. If I design a furniture line for a company that bears my name, it has to impress what I want it to be, because that is my product. I carry the name. I carry the brand. I carry the products. But, if I help a big corporation change their brand, then the job is different. I have to help them do it better, so I have to put myself aside and look at what is best for the brand. Bang \& Olufsen is a ninety-fiveyear-old brand. My five years with them as Creative Director was only a fragment of their history. It is a significant fragment because it made a big change, but at the same time, the company would have survived without me. It's important to understand where your impact is valid for the purpose, and it is also important to get your ego grounded. Then you can change things. Your ego is always playing a part. You always want to win. There is a motive. But it is also about understanding what you want. Do you want to do something that has impact? Well, then limit your ego and let your mind show you the way.

I would imagine that there are companies that want to use your name as a sales tool? Yes. Our contracts in that case state that people can use my name but I have to approve every step of the process. I have to make sure that what I put my name on actually gives me something that is good enough. We can have a vision, we can do fantastic drawings, everything is perfect, but if the company that has to execute it does not do a good job, our name is on stake as well. I am very, very careful and our contract states very clearly that we have to approve everything and we have the right to waive our name from it.

What is irritating is that sometimes you do projects where the intention is good, it starts well, you work, and it ends up that you have to withdraw your name. If it is a big project, it can take two years out of your time, and when the result ends up being poor, you have to withdraw your name. You actually have a blank period of time in your resume, which is not a good thing. It is really important to choose the right clients as well, it is not only about getting a big project and getting through cash. You also need to know that you have something to show the world.

So, in the end, a lot of what you do is based on sensory knowledge. How do you explain your team what you mean when you "feel" the idea? 
It is like conducting an orchestra as a conductor, the most important role is to hire the best. The best in each field, people who master their instrument. Your role then is to conduct them and that is the hardest work, because they are all individuals and they are all mastering the instruments perfectly, but they are all human beings, with souls, with families, meaning that they are completely different. This means that your role is not only to do the conducting part but also to have the understanding of human beings and how to look at them as individuals and put them together in the right composition so that you get a masterpiece from your direction.

What typically happens is: I have an idea, I put something on a piece of paper, a very naïve design in the beginning. The reason why I make it very naïve is because I want the creative team to get the same pictures as I do. If I say "I want exactly that," then I get that but then I could just go and do it myself. So if I want to get the best out of my creative team, I have to conduct them; I need to let them play their roles as the individuals they are. I need to let them look at my drawing and let them start elaborating. Because designers are driven by "Whoah! This will be great." And my role is to engage their creativity, so they will enjoy doing the work. I want them to feel it, so it becomes floating, it becomes personal.

Then, afterwards it is my role to do the opposite which is the difficult part. Which means that I have to get them to narrow it down, but I have to give them the acumen of the "why." If I say "just do what I say" then they do not want that. I want them to say: "Thank you, you make me a better musician. Now I play with even more feeling." It is a very difficult thing, but this is how you get the juice out of the people, which is really my role. It is my role and my job as well to get them to understand and to learn in the best way.

\section{Conclusion}

Although the design thinking literature posits that a designer's sensibility plays a key role in matching people's needs with what is technologically feasible and strategically acceptable (e.g., Brown, 2008; Stephens \& Boland, 2015), organizational research has rarely explored, to date, the role of designers as sources of variability and creativity in the design process. In recent years, several professional designers have observed that design thinking is too outward (SimpsonLittle, 2016), obsessed with prescription (Jen, 2018), fundamentally conservative (Iskander, 2018) or otherwise resulting in copycat products that lack uniqueness and differentiation (Ersoy, 2018). These concerns and critiques are usually published in periodicals and blogs of the designer community, a fact that makes it less likely for organizational scholars to access and consider them. We believe that organizational researchers who study design can extract substantial benefits from listening to designers' opinions and experiences. Our purpose in this article was to stimulate greater scholarly interest in exploring the designer behind the process of design thinking, in this case Johannes Torpe. Reflecting in retrospect on our conversations with Torpe, we found particularly useful the design thinking frameworks proposed by Dunne and Martin (2006) and Stephens and Boland (2015). We also identified in our interview material four interesting implications for future research.

First, with regard to the attitudinal aspects of design thinking (Dunne \& Martin, 2006), we found interesting that Torpe's attitude is not limited to the proximal technological, economical, or/and practical constraints posed by any given design project, but rather, it is propelled by a more general attitude towards constraints acquired through lived experience during his upbringing and adult life. We believe that it would be useful for future research to employ idiographic and biographical methodologies in order to better understand the designer behind the process of design thinking (cf. Bennis, 2003; Cameron, 2003; Weick, 2003).

Second, with regard to the interpersonal aspects of design thinking (Dunne \& Martin, 2006), we found interesting that Torpe talked to us not merely about the importance of empathizing with the users' and peers' needs and perspectives, but most importantly about the importance of ensuring ex ante the quality of the interpersonal relationships among designers, peers, and customers. We believe that future research can further explore Torpe's practice of choosing carefully projects and customers as well as design collaborators in his studio.

Third, with regard to the cognitive aspects of the design thinking (Dunne \& Martin, 2006), we found it interesting that Torpe talked to us about the importance of reasoning not only in terms of solving customers' problems but also in terms of tackling issues of creative identity within his own design studio. Considering that designers are usually hired by large corporations to solve a range of organizational problems, future research can examine how design studios tackle their own organizational problems, especially as they grow in size and reputation.

Finally, we found interesting that for Torpe emotions and bodily senses are implicated in how he experiences creative passion, how he relates to customers and peers, and also how he approaches various problems in the design process. Following Stephens and Boland (2015), we believe that future organizational research should focus more on the role of aesthetic forms of knowing in the design thinking process. Considering that design thinking is often described as "a human-centered approach to innovation that puts the observation and discovery of often highly nuanced, even tacit, human needs right at the forefront of the innovation process" (Gruber et al., 2015, pp. 1-2), we believe that research on the aesthetic knowledge of designers may offer the most direct link between the designer's subjective experiences when designing and the human needs of customers. 


\section{Declaration of Conflicting Interests}

The author(s) declared no potential conflicts of interest with respect to the research, authorship, and/or publication of this article.

\section{Funding}

The author(s) received no financial support for the research, authorship, and/or publication of this article.

\section{ORCID iD}

Marc Stierand iD https://orcid.org/0000-0002-4384-6431

\section{References}

Ben-Yehuda, A. (2008). Something to dance about. Billboard, ProQuest Business Collection, 120(5), 40.

Bennis, W. (2003). Frank Gehry: Artist, Leader, and „Neotenic”. Journal of Management Inquiry, 12(1), 81-87.

Brown, T. (2008). Design thinking. Harvard Business Review, $86(6), 84-92$.

Cameron, K. S. (2003). Organizational transformation through architecture and design: A project with Frank Gehry. Journal of Management Inquiry, 12(1), 88-92.

Chiva, R., \& Alegre, J. (2009). Investment in design and firm performance: The mediating role of design management. Journal of Product Innovation Management, 26(4), 424-440.

Dunne, D., \& Martin, R. (2006). Design thinking and how it will change management education: An interview and discussion. Academy of Management Learning \& Education, 5(4), 512-523.

Ersoy, L. A. (2018). Why design thinking is failing and what we should be doing differently. UX Collective. Retrieved from https://uxdesign.cc/why-design-thinking-is-failing-and-whatwe-should-be-doing-differently-c8842f843b44

Gruber, M., de Leon, N., George, G., \& Thompson, P. (2015). From the editors: Managing by design. Academy of Management Journal, 58(1), 1-7.

Iskander, N. (2018). Design thinking is fundamentally conservative and preserves the status quo. Harvard Business Review. Retrieved from https://hbr.org/2018/09/design-thinking-is-fundamentally-conservative-and-preserves-the-status-quo.
Jen, N. (2018). Design thinking. Fast Company. Retrieved from https://www.fastcompany.com/90166804/design-thinking-is-b-s

Jones, C., Anand, N., \& Alvarez, J. (2005). Guest Editors' Introduction: Manufactured authenticity and creative voice in cultural industries. Journal of Management Studies, 42(5), 893-899.

Lahey, J. (2017). How design thinking became a buzzword at school. The Atlantic. Retrieved from https://www.theatlantic. com/education/archive/2017/01/how-design-thinking-becamea-buzzword-at-school/512150/

Lampel, J., Lant, T., \& Shamsie, J. (2000). Balancing act: Learning from organizing practices in cultural industries. Organization Science, 11(3), 263-269.

Mainemelis, C. (2010). Stealing fire: Creative deviance in the evolution of new ideas. Academy of Management Review, 35(4), 558-578.

Mainemelis, C., Kark, R., \& Epitropaki, O. (2015). Creative leadership: A multi-context conceptualization. Academy of Management Annals, 9(1), 393-482.

Nussbaum, B. (2011). Design thinking is a failed experiment. So what's next? Fast Company. Retrieved from https://www. fastcompany.com/1663558/design-thinking-is-a-failed-experiment-so-whats-next

Simpson-Little, D. (2016). 5 alternative approaches to design thinking. Creative Bloq. Retrieved from https://www.creativebloq. com/advice/5-alternative-approaches-to-design-thinking

Stephens, J. P., \& Boland, B. J. (2015). The aesthetic knowledge problem of problem-solving with design thinking. Journal of Management Inquiry, 24(3), 219-232.

Stierand, M. (2015). Developing creativity in practice: Explorations with world-renowned chefs. Management Learning, 46(5), 598-617.

Stierand, M., Dörfler, V., \& MacBryde, J. (2014). Creativity and innovation in haute cuisine: Towards a systemic model. Creativity and Innovation Management, 23(1), 15-28.

Vinsel, L. (2018). Design thinking is a boondoggle. The Chronicle of Higher Education. Retrieved from https://www.chronicle. com/article/Design-Thinking-Is-a/243472

Weick, K. E. (2003). Organizational design and the Gehry experience. Journal of Management Inquiry, 12(1), 93-97. 